\title{
Thermal Image Analysis of Plastic Deformation and Fracture in Notched Members
}

\author{
Hidetoshi SAKAMOTO, Jian SHI and Keisuke MORI \\ Department of Mechanical Engineering \& Materials Science, Kumamoto University, \\ 2-39-1 Kurokami Kumamoto 860-8555 Japan
}

We tried to evaluate the plastic zone size and fracture behavior by analyzing the surface's thermal image of heat generation which was exhausted by plastic deformation. By continuous comparing the change of surface's temperature distributions between thermography method and thermocouples method, we showed the validity of the thermal image of heat generation under plastic deformation by using thermograophy method and the effective thermal image processing method. Furthermore CCD camera was used to observe the process of plastic deformation on the surface, the relations between CCD image and the thermal image was discussed.

Key Words : Infrared thermography, Thermal image, CCD image, Image processing, Plastic deformation, Fracture.

\section{Introduction}

Infrared thermography is a good effective method to detect the two-dimensional heat distribution of materials surface with non-contact and in real time. As this application, some papers had discussed the detection of cracks or defect, the measurement of stress intensity and the strain distribution $[1,2,3]$ and so on

In this paper, we paid attention to heat generation that had exhausted by plastic deformation and fracture and we tried to evaluate the plastic deformation and fracture behaviors in strain rate sensitivity material[4][5]. Furthermore, the relation between the state of specimen's surface and the thermal image in plastic deformation under tensile load was discussed. The state of specimen's surface was measured by $\mathrm{CCD}$ camera and $\mathrm{CCD}$ images were recorded by VTR.

\section{Experiments}

\subsection{Material and specimen}

The material used is $99.9 \%$ pure titanium that have remarkable strain rate sensitivity at room temperature. The geometry and dimensions of specimen are indicated in Fig. 1 and the mechanical properties of Titanium are given in Table 1. The center pre-crack was made by Electrospark machine with $0.3 \mathrm{~mm}$ diameter as stress concentration parts. The test specimens were cut out from rolling direction and transverse to rolling direction of plate in order to examine
Table 1 Mechanical properties of Titanium

\begin{tabular}{|c|c|c|c|}
\hline & $\begin{array}{c}\text { Young's modulus } \\
(\mathrm{GPa})\end{array}$ & Poisson' ratio & $\begin{array}{c}\text { Yield stress } \\
(\mathrm{MPa})\end{array}$ \\
\hline Roll & 117 & 0.34 & 245 \\
\hline Trans & 198 & 0.35 & 198 \\
\hline
\end{tabular}

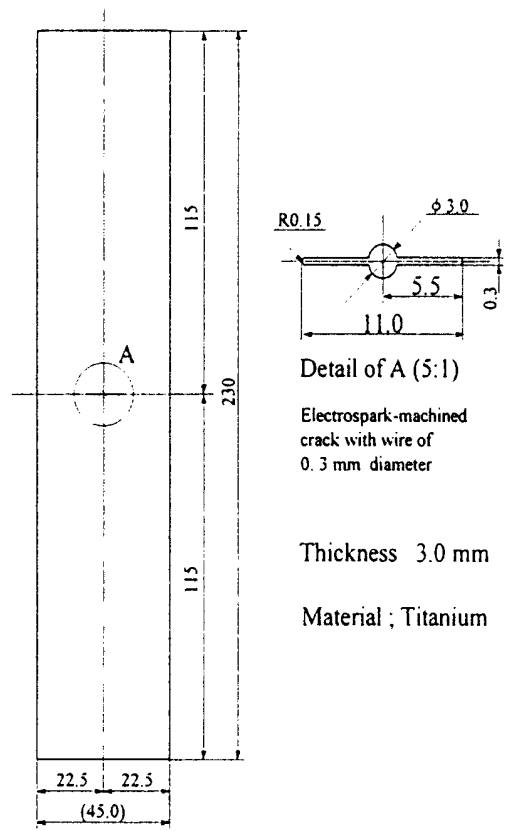

Fig. 1 Geometry and dimensions of test specimen 
the effect of anisotropy. We carried out experiments to both directions' specimens with two loading speeds $(50 \mathrm{~mm} / \mathrm{min}, 5 \mathrm{~mm} / \mathrm{min})$ in order to examine the effect of anisotropy and strain rate dependence on the plastic deformation and fracture behaviors. Figures 2(a) and 2(b) show the stress-strain relations of each direction in loading speeds $(5,50 \mathrm{~mm} / \mathrm{min})$ respectively.

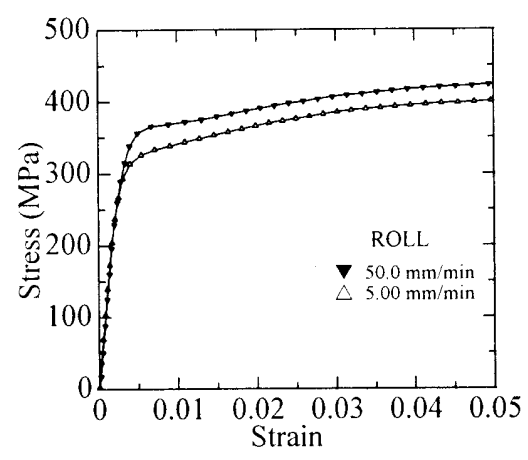

(a) Roll direction

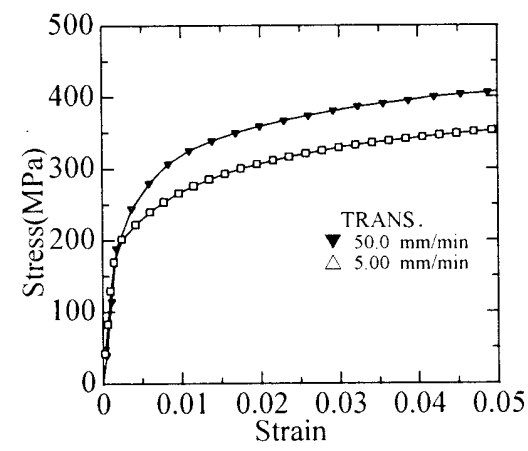

(b) Transverse direction to roll

Fig. 2 Stress-strain relations

\subsection{Experimental method}

Photograph 1 shows the CCD camera and the displacement measurement unit. This camera was used in measurement of the COD and observation of the surface states around the crack tip under plastic deformation. The clip-gage shown in Photo.1 was used to measure the displacement (gage length $50 \mathrm{~mm}$ ). The COD was measured at $1 \mathrm{~mm}$ distance from crack tip by CCD image processing.

Figure 3 shows the thermal image detecting system. The thermal camera measured the heat distributions of specimen's surface. Thermocouples were welded on the specimen surface by electro spark at four points shown in Fig. 4. These were necessary as a calibration with temperature measured by thermo-viewer

The specification of the infrared thermal video system (TVS-8200) is shown in Table 2.

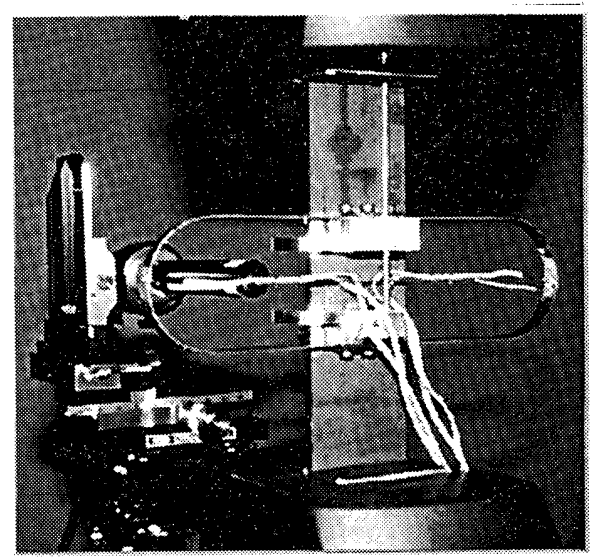

Photo $1 \mathrm{CCD}$ camera and displacement measuring unit

Table 2 Specification of TVS- 8200

\begin{tabular}{ll}
\hline Range of measurement temperature & $-40-1200^{\circ} \mathrm{C}$ \\
Resolution of temperature & $0.4 \%$ \\
Number of scanning frames & 60 frames $/ \mathrm{sec}$ \\
Display elements & 76800 pixels \\
Detector & $\operatorname{InSb}(\mathrm{H} 160 \times \mathrm{xV} 120$ elements $)$ \\
Detecting wave rang & $4-4.6 \mu \mathrm{m}$ \\
\hline
\end{tabular}

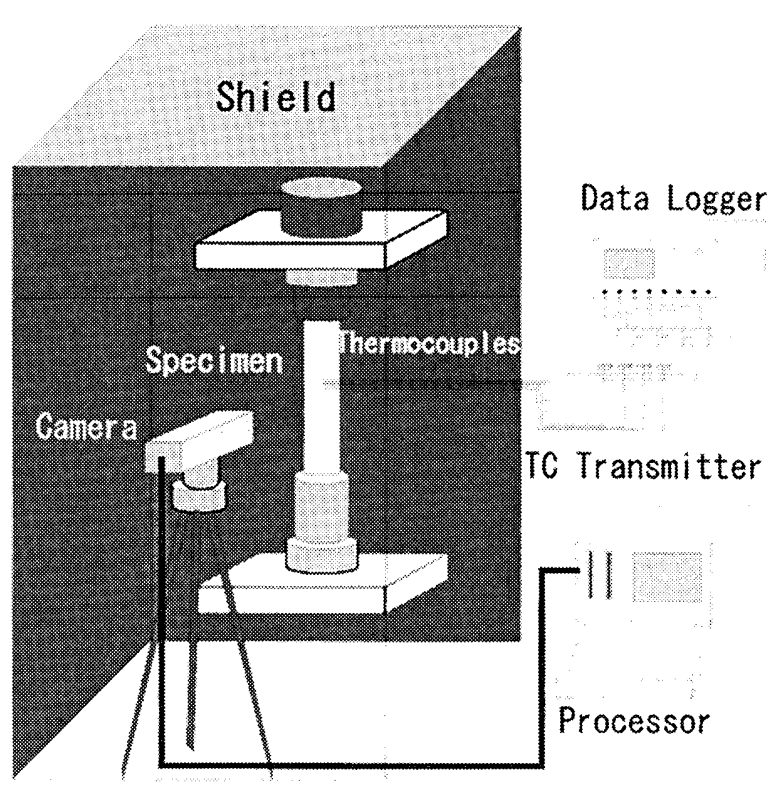

Fig. 3 Thermal image detecting system (TVS system) 


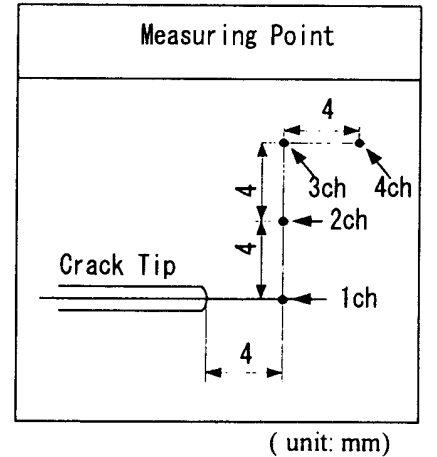

Fig. 4 Measuring points by thermocouples

\section{RESULTS AND DISCUSSION}

Figures 5(a),(b) and 6(a),(b) show the measurement results of $C O D$ and clip-gage disp

lacement, respectively. From those figures, the clip-gage displacement are almost same with the COD at low loading speed, $5 \mathrm{~mm} / \mathrm{min}$.

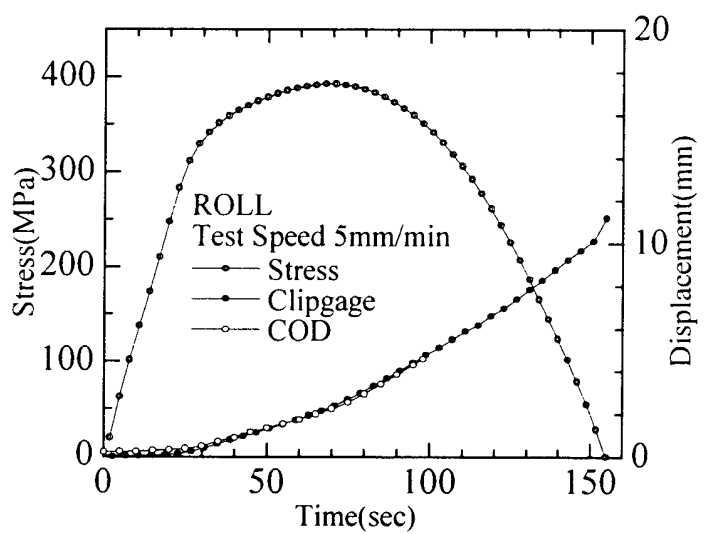

(a) $\mathrm{v}=5 \mathrm{~mm} / \mathrm{min}$

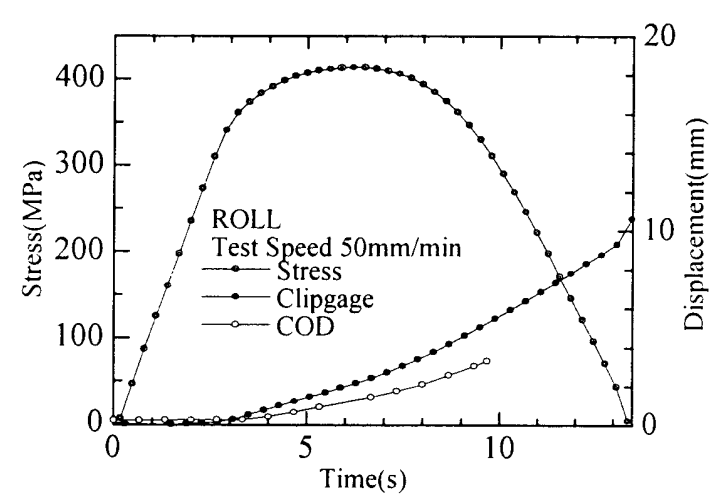

(b) $\mathrm{v}=50 \mathrm{~mm} / \mathrm{min}$

Fig. 5 Clip-gage displacement and COD (Roll Dir.)

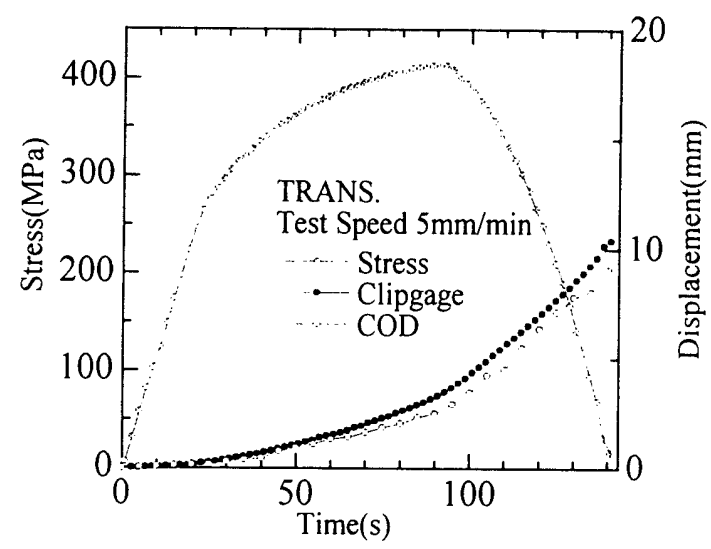

(a) $v=5 \mathrm{~mm} / \mathrm{min}$

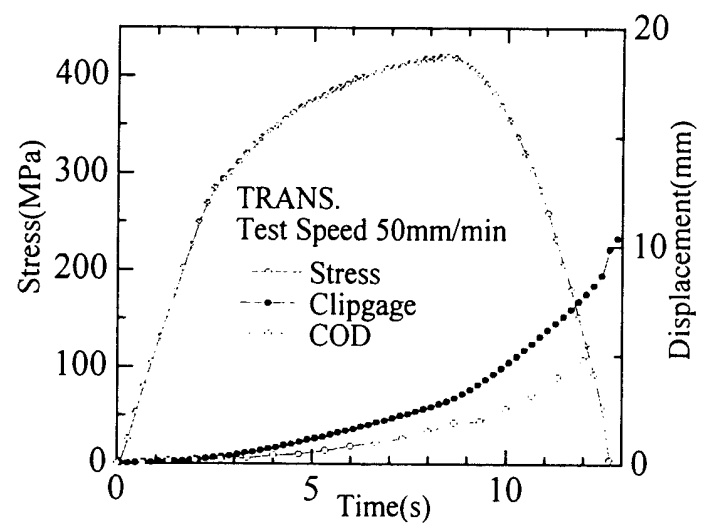

(b) $\mathrm{v}=50 \mathrm{~mm} / \mathrm{min}$

Fig. 6 Clip-gage displacement and COD (Trans. Dir.)

But, in the case of high loading speed, $50 \mathrm{~mm} / \mathrm{min}$, the clip-gage displacement is larger than that of COD with increasing displacement. This phenomenon is due to strain concentration caused by material's strain rate dependence. Comparing between the rolling and the transverse direction, the COD and the clip-gage displacement of roll direction are larger than those of transverse direction at same loading speeds.

Figures $7(a) \sim(d)$ and $8(a) \sim(d)$ show the temperature rises at four points around crack tip shown in Fig. 4 by thermocouples and thermo-viewer. At the same speed, the temperature of point 1 is higher than that of other three points. The temperatures of point 2 and point 4 are higher than that of point 3 , because point 2 and point 4 were located in principle shearing stress region. The temperatures measured by thermocouples are little higher than that of measured by thermo-viewer, but both tendencies of temperature rise showed good agreement. 


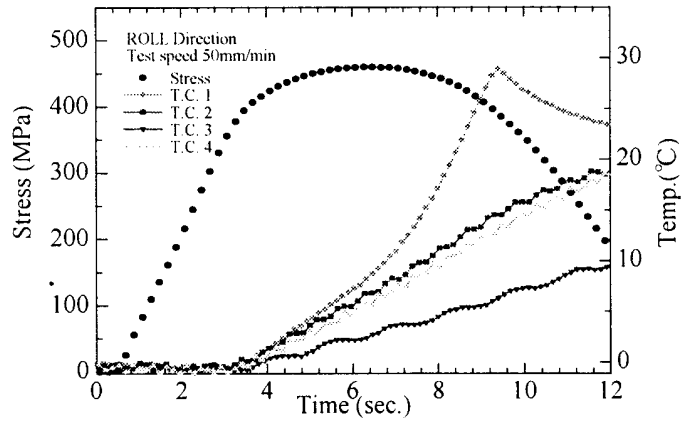

(a) Thermocouples $(v=50 \mathrm{~mm} / \mathrm{min})$

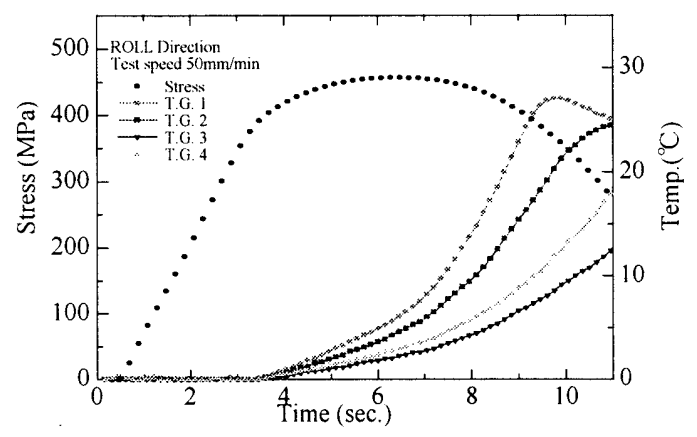

(b) thermo-viewer $(v=50 \mathrm{~mm} / \mathrm{min})$

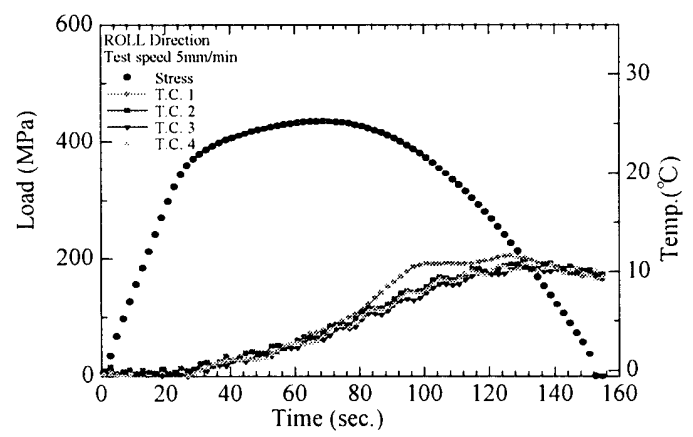

(c) Themocouples $(v=5 \mathrm{~mm} / \mathrm{min})$

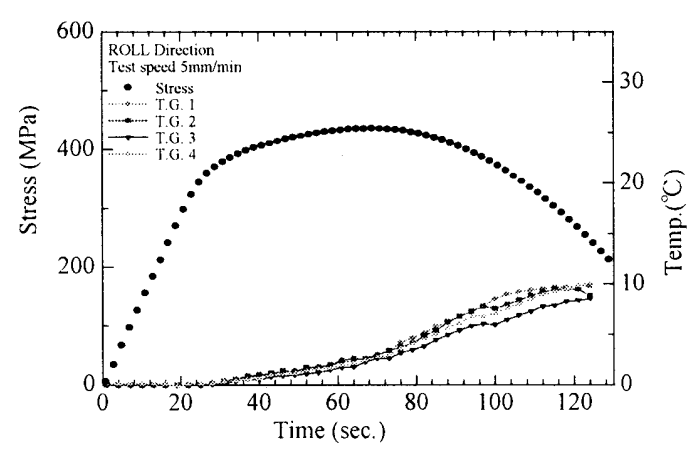

(d)Thermo-viewer $(v=5 \mathrm{~mm} / \mathrm{min})$

Fig.7 Temperature rise around crack tip (Roll dir.)

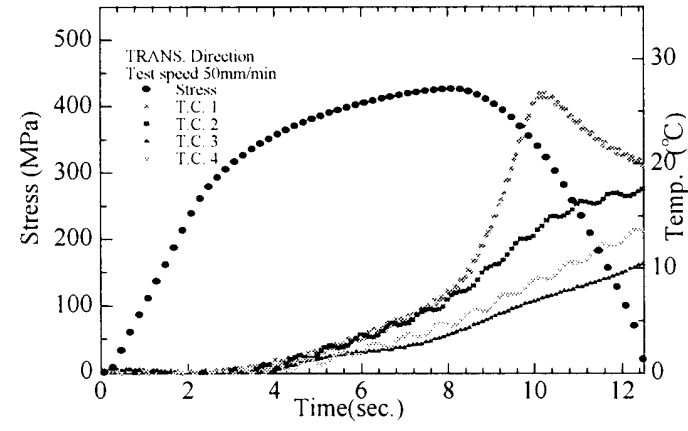

(a) Thermocouples $(v=50 \mathrm{~mm} / \mathrm{min})$

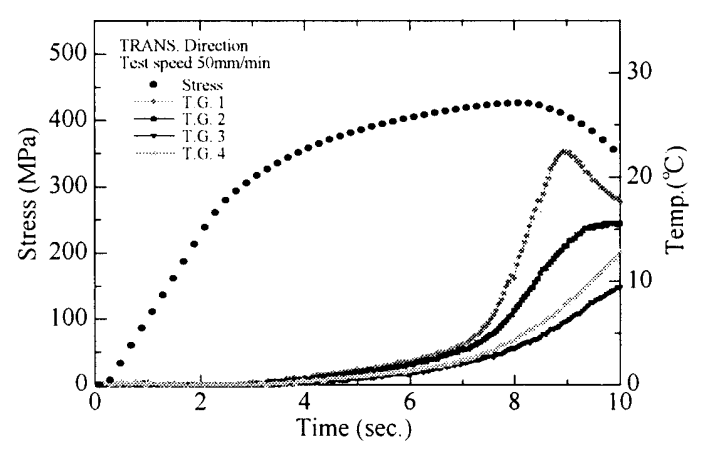

(b) Thermo-viewer $(v=50 \mathrm{~mm} / \mathrm{min})$

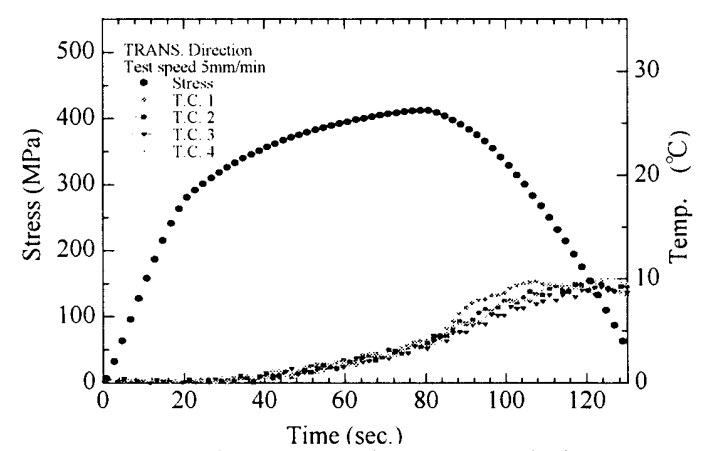

(c) Thermocouples $(\mathrm{v}=5 \mathrm{~mm} / \mathrm{min})$

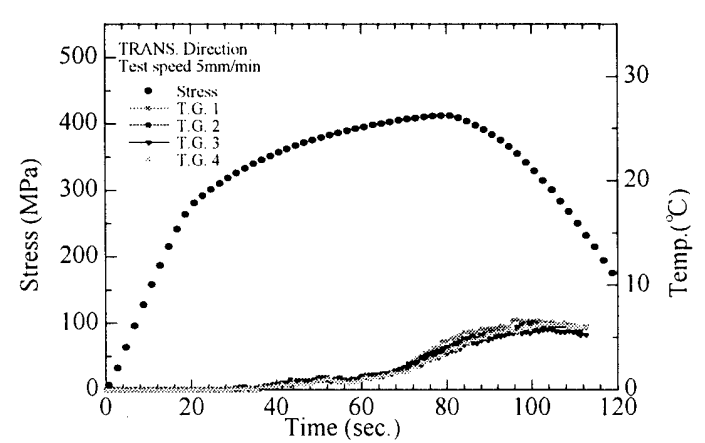

(d) Thermo-viewer $(v=5 \mathrm{~mm} / \mathrm{min})$

Fig.8 Temperature around crack tip (Trans. dir.) 
Paying attention to the different of loading speed, the temperature around crack tip at $50 \mathrm{~mm} / \mathrm{min}$ increase rapidly compared with that at $5 \mathrm{~mm} / \mathrm{min}$ because of strain concentration and short time for heat conduction. In the rolling direction, this tendency was distinguished.

Figures 9(a) and (b) show the comparison of the thermal images between the rolling direction and transverse to rolling direction at $50 \mathrm{~mm} / \mathrm{min}$. We can recognize the difference of plastic deformation behaviors due to material's anisotropy by detecting the surface temperature distributions.
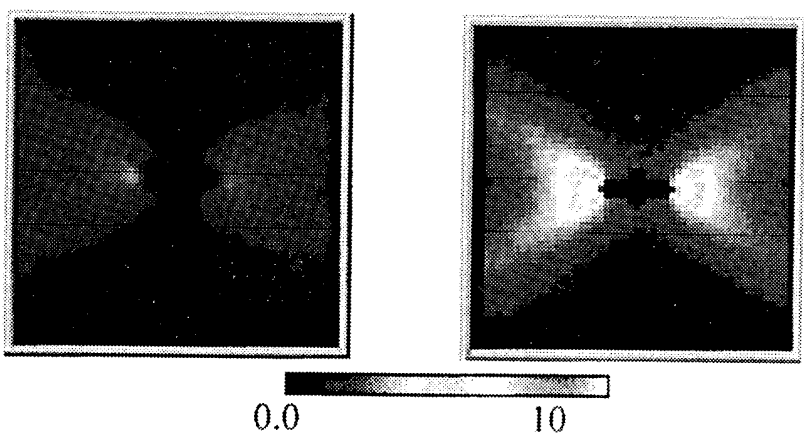

10
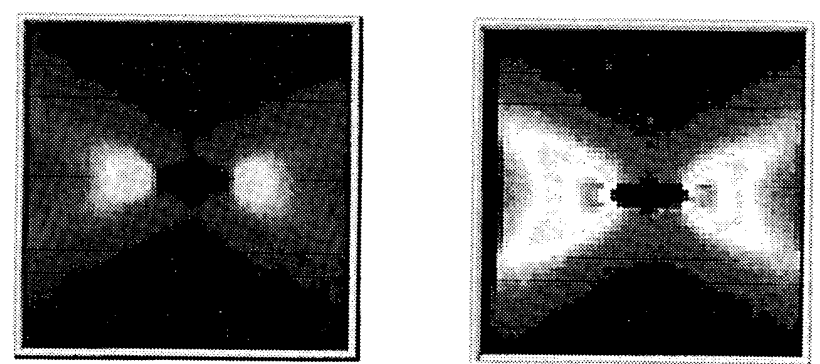

0.0

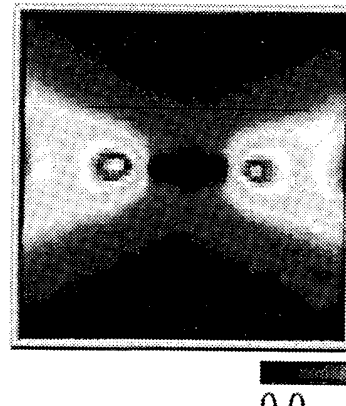

(a)Trans. Dir.

10

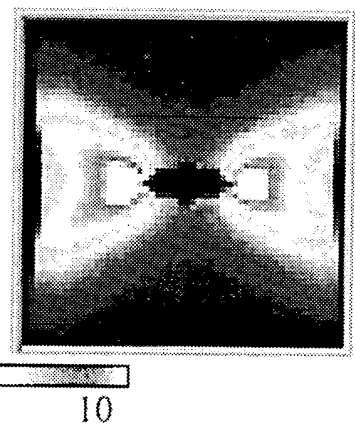

(b) Roll. Dir.

Fig. 9 Comparison of the thermal images between rolling dir. and transverse dir.

$$
(\mathrm{v}=50 \mathrm{~mm} / \mathrm{min})
$$

Figures $10(a)$ and (b) show a example of the CCD image and the corresponding thermal image by thermo-viewer. It is found that the CCD image is good corresponding to the thermal image. From these figure, in the case of high loading speed, it is found that thermal image shows macroscopic plastic deformation.

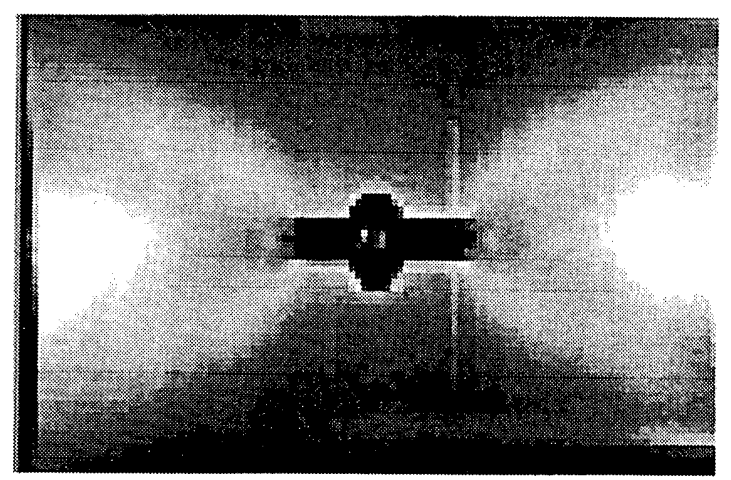

(a) CCD image

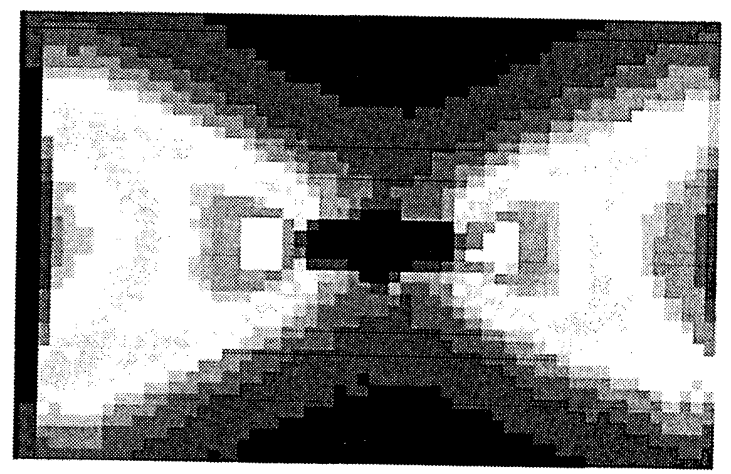

(b) Thermal image

Fig. 10 Comparison between CCD image and thermal image by thermo-viewer

\section{Conclusions}

The results obtained are summarized as follows;

(1) The surface temperatures detected by thermo-viewer are in good agreement with heat generation by plastic deformation.

(2) The difference of the deformation behavior in strain rate dependence and anisotropy of the pure titanium plate can be obtained by thermal image analysis.

(3) The local plastic deformation and local plastic region could be evaluated from the thermal image.

(4) In the case of loading speed, thermal image expresses the macroscopic plastic behaviors. 


\section{References}

(1) Osakada, K., Shinagawa, K. and Kayama, S., Advanced Technology of Plasticity, China, (1933),pp. 257-262.

(2) Luong, M.P., IUTAM Symposium on Micro- and Macrostructural Aspects of Thermoplasticity, (1999), pp.437-446.

(3) Shiratori,M., JSME Int. Journal, Ser. I , Vol.33, No.3 (1990), pp. 400-408.

(4) Oda, I., Doi,T., Sakamoto H., and Yamamoto, M., Trans. Jpn. Soc. Mech. Eng., (in Japanese), C, Vol.60, No.578(1994), pp.314-319.

(5) Sakamoto, H., Oda I., Doi, T., Hirose,O, and Yamamoto, M., Trans. Jpn. Soc. Mech. Eng., (in Japanese), A, Vol.62, No.600(1996), pp.80-85. 